\title{
Recanalization of arterial duct is feasible, effective and its potential risks are treatable
}

\author{
Milad EL-SEGAIER ${ }^{1,2}, \mathrm{MD}$, PhD; Mohammed O. GALAL ${ }^{1,3}, \mathrm{MD}$, PhD; Ghada SHIEKH ELDIN MD ${ }^{1}$, \\ Tarek MOMENAH ${ }^{1}$, MD \\ ${ }^{1}$ Dept. of Paediatric Cardiology, King Fahad Medical City, PSHC, Riyadh, Saudi Arabia; ${ }^{2}$ Dept. of Paediatric Cardiology, Skåne University \\ Hospital, Lund, Sweden; ${ }^{3}$ Dept. of Paediatric Cardiology, Essen University, Essen, Germany.
}

\section{Background Recanalization of arterial duct (AD) is rarely needed.}

Objective The aim of this study is to report our experience regarding the feasibility and effectiveness of arterial duct recanalization in three infants and review the relevant literature.

Methods and results We report on three patients with decreased pulmonary blood flow after initial palliation. The first patient had pulmonary atresia (PA) and an intact ventricular septum. He needed recanalization of the $A D$ after pulmonary valve perforation and dilatation. The second patient had PA and ventricular septal defect (VSD). His AD originated from the left subclavian artery. He required AD recanalization after palliation with a central shunt and clipping of the duct. During intervention he developed a thrombus in the stent, which was treated successfully using thrombolytic treatment. The third patient had PA and VSD. The arterial duct originated from the left subclavian artery and was recanalized after spontaneous closure despite prostaglandin infusion. During the procedure the patient had severe desaturation and bradycardia requiring resuscitation for two minutes. All infants had successful arterial duct recanalization and stenting. Additionally, they were clinically stable during follow-up.

Concl usion Arterial duct recanalization and stenting is a feasible and effective procedure in selected cases, and its risks are treatable. Long-term studies are required.

Keywords Arterial duct recanalization - stent-stent thrombosis - congenital heart disease.

\section{INTRODUCTION}

Patency of the arterial duct (AD) needs to be preserved for a certain time in patients with duct-dependent circulation. Prostaglandin infusion is the treatment of choice to keep the arterial duct patent for a short period $^{1}$. Palliation with systemic-to-pulmonary shunt or stenting of the $\mathrm{AD}$ is the standard procedure prior to surgical correction ${ }^{2,3}$. However, occasionally after

Address for correspondence:

Milad El-Segaier, MD, PhD,

Dept. of Paediatric Cardiology, King Fahad Medical City, PSHC, Riyadh, Saudi Arabia.

E-mail: milad.el-segaier@med.lu.se

Received 10 April 2014; revision accepted for publication

30 September 2014. successful initial palliation, a secondary intervention is needed to maintain adequate pulmonary blood flow. To the best of our knowledge, seven successful cases of $\mathrm{AD}$ recanalization have been reported: two case reports and one case series including six patients ${ }^{4,5,6}$.

The aim of the current paper is to report our experience with three infants less than two months of age with inadequate pulmonary blood supply despite successful initial palliation or on prostaglandin infusion. In all three patients, the $\mathrm{AD}$ was successfully recanalized using the percutaneous technique.

\section{METHODS AND RESULTS}

\section{First case}

A male infant aged 4 days and weighing $2.8 \mathrm{~kg}$ with cyanosis (saturation $81 \%$ ) was started on prostaglandin infusion (30 ng/kg per min). Echocardiography revealed 
membraneous pulmonary valve atresia with an intact ventricular septum. The tricuspid valve size was $0.97 \mathrm{~cm}$ (z-value 1.2) and the right ventricle was tripartite. The $\mathrm{AD}$ was patent with left aortic arch. At the age of seven days, the infant underwent pulmonary valve perforation and balloon valvuloplasty. The saturation improved to $90 \%$ in room air, and prostaglandin infusion was discontinued. A few hours later, the saturation decreased to $80 \%$. Repeated echocardiography revealed there was a moderate subvalvular pulmonary stenosis with Doppler systolic gradient of $40 \mathrm{mmHg}$ and patent $\mathrm{AD}$. The infant was well hydrated and treated with phentolamine and angiotensin-converting enzyme inhibitor ${ }^{7,8}$. Saturation during the following 11 days fluctuated between 65-80\%. Despite supportive management, saturation remained low $(\sim 60 \%)$. At the age of 23 days the patient was taken to cardiac catheterization for $\mathrm{AD}$ stenting.

\section{Second case}

This male infant weighed $2.9 \mathrm{~kg}$ at birth and was noted to have low saturation (83\%). Echocardiography showed pulmonary atresia with VSD, right aortic arch and large $\mathrm{AD}$ originating from the left subclavian artery. There was additionally proximal left pulmonary artery stenosis. Prostaglandin infusion (30 ng/kg per min) was started. Due to the left pulmonary artery stenosis, the infant was referred for central aorto-pulmonary shunt at the age of 23 days. At operation, a 4-mm central Goretex shunt was inserted and the $\mathrm{AD}$ was clipped. One week after surgery, the infant started to desaturate. Echocardiography showed a patent central shunt with occluded AD. The left pulmonary artery branch was difficult to visualize. Two weeks later, due to persistent low saturation $(\sim 65 \%)$, the infant was taken to cardiac catheterization for evaluation.

\section{Third case}

This boy was referred to our institute at the age of 45 days with a body weight of $3.1 \mathrm{~kg}$. He had been diagnosed with pulmonary atresia, VSD and a large AD at a peripheral hospital. The patient was on prostaglandin infusion (20 ng/kg per min). Saturation was $87 \%$. Echocardiography confirmed the diagnosis and showed right aortic arch with the $\mathrm{AD}$ originating from the left subclavian artery.

\section{PROCEDURES}

All procedures were done under general anaesthesia. After femoral artery access, aortography was performed using a 4-Fr pigtail catheter in lateral and either LAO or
AP view. Thereafter, the sheath was exchanged with a long one ( $4 \mathrm{Fr}, 23 \mathrm{~cm}$ ) to give better support during stent deployment. Heparin boluses were given to keep the activated clotting time (ACT) above 220 seconds. Cephazolin was also given.

\section{Procedure to the first case}

Aortography showed a closed AD with small indentation at the site of the ductal ampulla (figure 1a). Through a 4-Fr Judkins right 4 catheter, a floppy-II, 0.014-inch PTCA wire (Abbott, Santa Clara, California, USA) was advanced, unexpectedly easily, across the occluded AD (figure 1b). A contrast injection was done within the closed AD. The duct length was $13 \mathrm{~mm}$. The catheter was withdrawn. An Integrity bare metal coronary stent (Medtronic, Minneapolis, USA), $4 \mathrm{~mm} \times 15 \mathrm{~mm}$ was advanced over the floppy wire and deployed across the $\mathrm{AD}$. The stent position was confirmed by an injection through the side arm of the sheath (figure 1c).

The saturation immediately increased from $60 \%$ to $88 \%$. One week later, the patient was discharged on aspirin $3 \mathrm{mg} / \mathrm{kg}$ per day and clopidogrel $0.5 \mathrm{mg} / \mathrm{kg}$ per day as an antiplatelet aggregation agent ${ }^{9}$. At the last follow-up, nine months later, the patient was showing normal development with a body weight of $8 \mathrm{~kg}$, saturation $93 \%$ and no complications from the antiplatelet aggregation therapy.

\section{Procedure to the second case}

Aortography showed a patent central shunt, but only the right pulmonary artery was visualized. A faint contrast flow to the left pulmonary artery was seen from the site of origin of the previous AD. Another hand injection was performed in the left subclavian artery, at the orifice of the clipped AD. This injection showed that there was a tiny track (14 mm in length) through the clipped duct supplying the left pulmonary artery (figure $2 \mathrm{a}$ ). We decided to recanalize and stent the clipped AD. With the support of the $23-\mathrm{cm}$ long sheath, an integrity bare metal coronary stent (Medtronic, Minneapolis, USA), $4 \mathrm{~mm} \times 15 \mathrm{~mm}$, was advanced easily, positioned, and then inflated across the clipped AD. Hand injection showed that the AD was successfully recanalized and stented. The subclavian artery end of the $\mathrm{AD}$ remained uncovered.

A trial to deploy another stent $(4 \times 8 \mathrm{~mm})$ to cover the remaining part of the $\mathrm{AD}$ led to desaturation and thrombus formation within the $\mathrm{AD}$ (figure $2 \mathrm{~b}$ ). The procedure was ended and the infant was transferred to the intensive care unit on heparin infusion $(15 \mu \mathrm{g} / \mathrm{kg}$ per min). An infusion of tissue plasminogen activator (tPA) was started with close monitoring. Within two hours the saturation increased to $80 \%$. There were no 

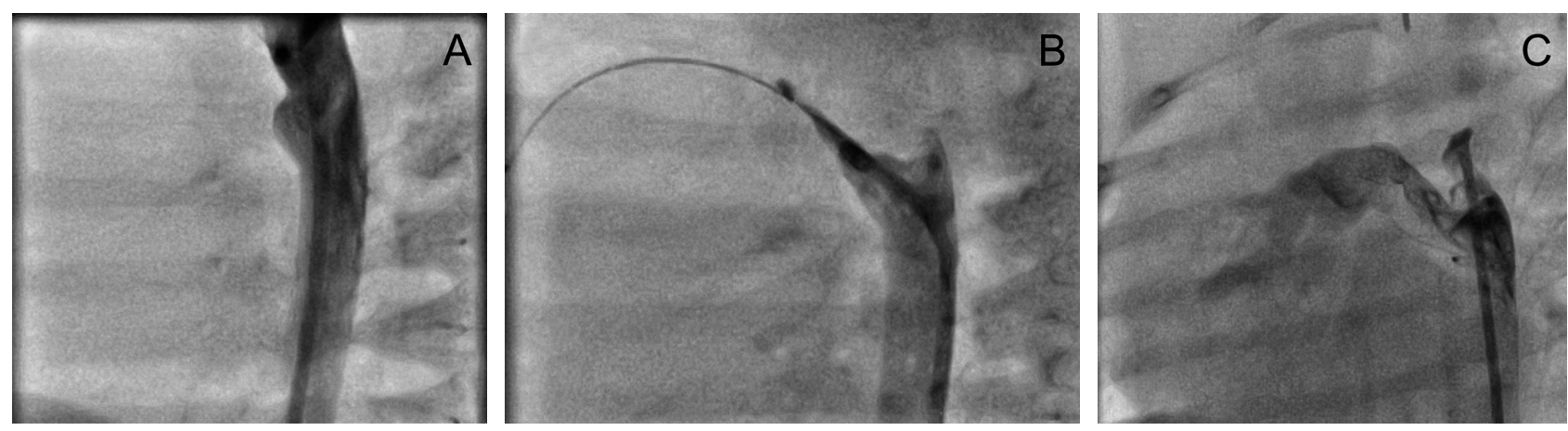

Fig. 1 Frozen frames

A: aortography with $\mathrm{AD}$ ampulla and closed $\mathrm{AD}$. B: the $\mathrm{AD}$ crossed by the wire. Contrast injection within AD demonstrating its morphology. C: the final result; a patent AD with stent in good position.
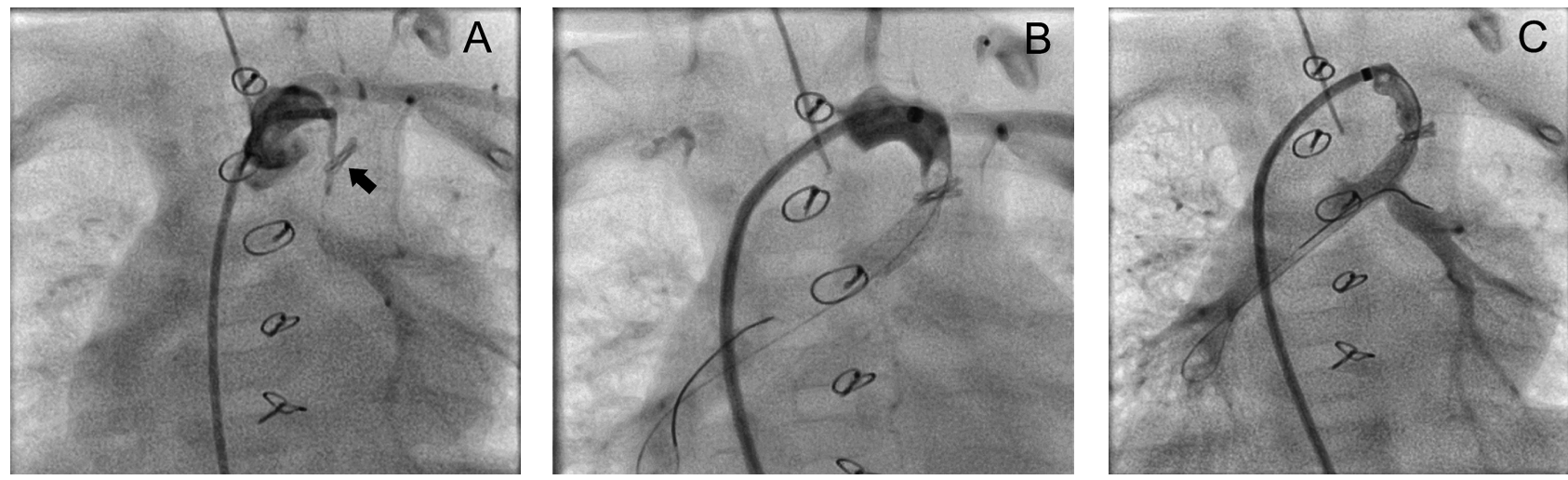

Fig. 2 Frozen frames

A: a contrast injection in the left subclavian artery. The ligated AD is seen as a narrow open canal with the clip in the middle of the canal (arrow). B: an injection at the orifice of the AD stent showing thrombus occluding the subclavian end of the stent. C: the final result; a patent AD stent.

complications related to tPA treatment. Repeated angiography, six hours later, revealed resolution of the thrombus with patency of the stent (figure $2 \mathrm{c}$ ). The infant was discharged eight days later on aspirin $(3 \mathrm{mg} /$ $\mathrm{kg}$ per day) and clopidogrel ( $0.5 \mathrm{mg} / \mathrm{kg}$ per day). Eleven months later and with functioning shunt and AD stent, the patient had no complications from antiplatelet aggregation therapy and had normal neurological development. He is awaiting further surgical repair.

\section{Procedure to the third case}

Aortography showed pulmonary atresia, right-sided aortic arch and a barely patent $\mathrm{AD}$ arising from the left subclavian artery. An attempt to advance a floppy-II, 0.014-inch PTCA wire (Abbott, Santa Clara, California, USA) into the $\mathrm{AD}$ ended in severe desaturation (50\%) and bradycardia (heart rate $40 \mathrm{bpm}$ ). Cardiac massage and resuscitation were started. The infant recovered within two minutes. A contrast hand injection showed a completely closed $\mathrm{AD}$ (figure $3 \mathrm{a}$ ). It was possible to advance the wire across the obliterated AD, and a PTCA balloon was used to reopen it. For better support, this wire was exchanged with 0.014-inch BMW wire (Abbott, Santa Clara, California, USA). As previously described, an integrity bare metal coronary stent (Medtronic, Minneapolis, USA), $(4 \mathrm{~mm} \times 21 \mathrm{~mm})$ was deployed in the $\mathrm{AD}$ covering its entire length. As the $\mathrm{AD}$ had a curved shape, it was not easy to pull back the balloon from the stent. To overcome this situation, the long sheath was advanced and held against the subclavian end of the stent (figure $4 \mathrm{a}, \mathrm{b}$ ). Thus the balloon could be withdrawn keeping the stent in place (figure $4 \mathrm{c}$ ). A final aortography showed a patent and well-positioned AD stent (figure $3 b$ ). The infant remained stable and was discharged within one week on aspirin $(3 \mathrm{mg} / \mathrm{kg}$ per day) and clopidogrel $(0.5 \mathrm{mg} / \mathrm{kg}$ per day). Ten months later, the infant had no complication from antiplatelet aggregation therapy, had normal neurological development, and underwent successful Rastelli repair.

The fluoroscopy time, contrast amount, weight, saturation and echocardiographic findings at follow-up of 
Fig. 3 Frozen frames A: a contrast injection in the left subclavian artery showing the $A D$ morphology. B: the final result; a patent $A D$ stent.
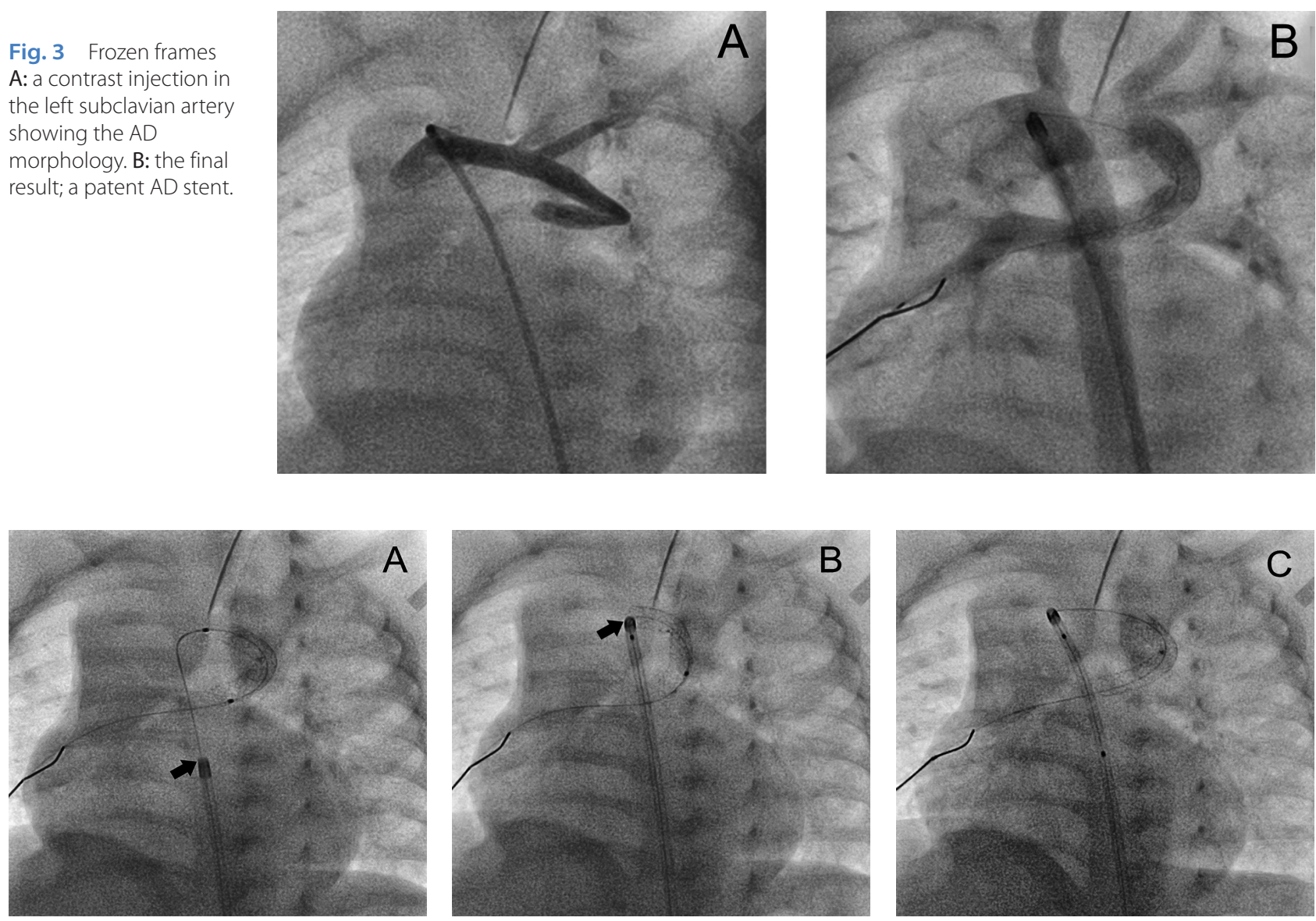

Fig. 4 Frozen frames

A: the tip of the long femoral sheath (arrow) in the descending aorta and the deflated balloon within the stent. B: the tip of the long femoral sheath held against the subclavian end of the stent. C: the balloon withdrawn within the long sheath, keeping the stent in place.

all three cases are presented in table 1. Summaries of reports in the literature regarding recanalization of the $\mathrm{AD}$ are presented in table 2.

\section{DISCUSSION}

\section{Literature review}

Over the last 15 years, $\mathrm{AD}$ stenting has been slowly introduced as an alternative to surgical systemic-to-pulmonary shunt ${ }^{3}$. Arterial duct recanalization has been described only sporadically as case reports ${ }^{4,5}$. There was only one case series of successful $\mathrm{AD}$ recanalization in five out of six infants, who were older than three months of age ${ }^{6}$.

\section{Current study}

We were encouraged by the few reported studies, especially when we encountered younger infants who might benefit from this intervention. Implantation of a systemic-to-pulmonary shunt was considered, but we thought that applying the concept of recanalization could put less stress on the patients. Our experience with the three patients we describe shows that $\mathrm{AD}$ recanalization and stenting are technically feasible and effective, with midterm benefit. However, one should be aware of the potential complications of this intervention and be prepared to manage them appropriately.

In our series, two patients were not able to maintain saturation shortly after palliation (either pulmonary valve perforation and dilatation or central systemic-topulmonary shunt), and they required further intervention to increase pulmonary blood flow. One option was to subject them to a second surgical intervention, but the alternative was to recanalize the $\mathrm{AD}$.

\section{The benefits}

In contrast to surgical shunt implantation, the ductal stent is less invasive, non-surgical and more convenient for neonates requiring multiple surgeries in the future. The intervention also requires a shorter hospital stay $^{10,11,12}$. Additionally, after AD stenting there is better uniform growth of pulmonary artery branches, leading 

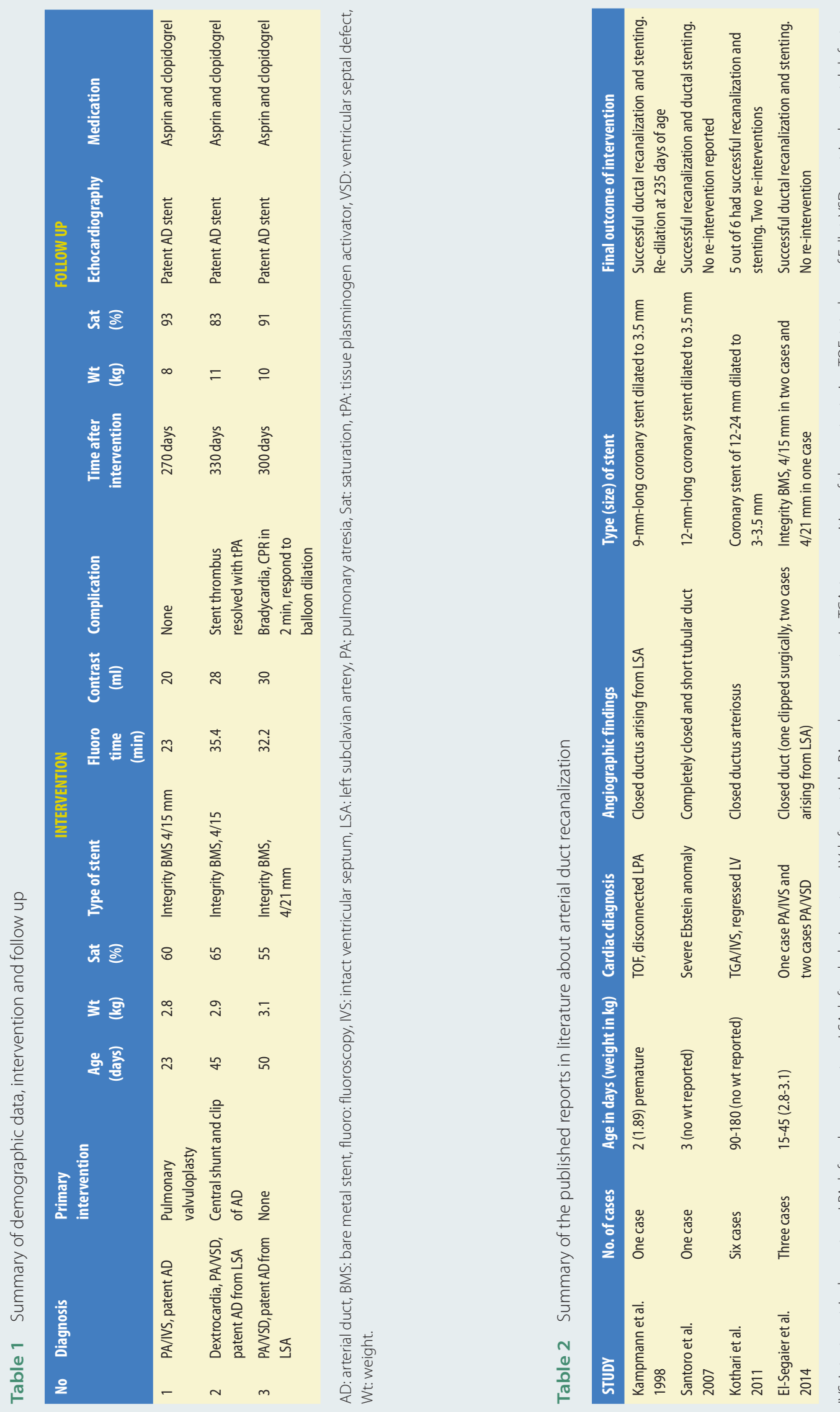

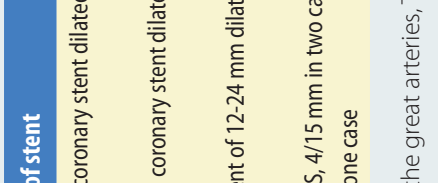

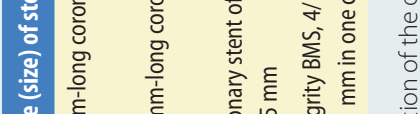

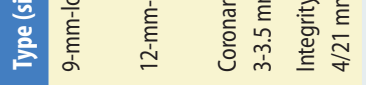

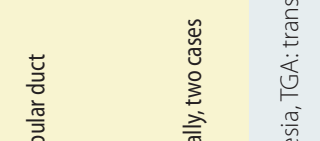

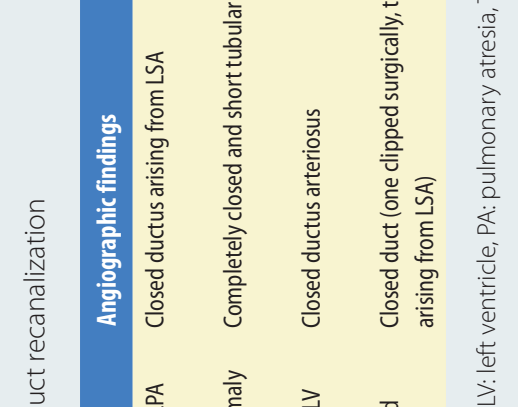

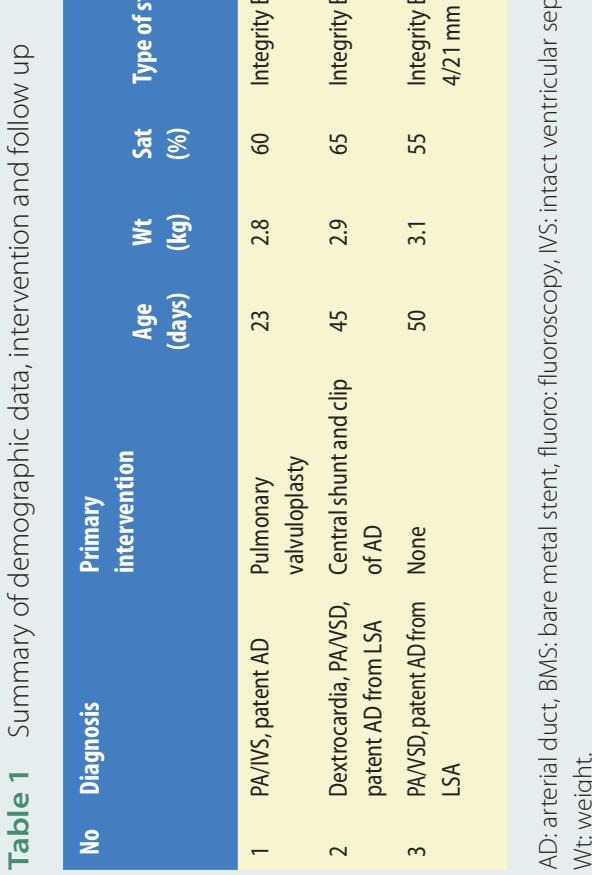

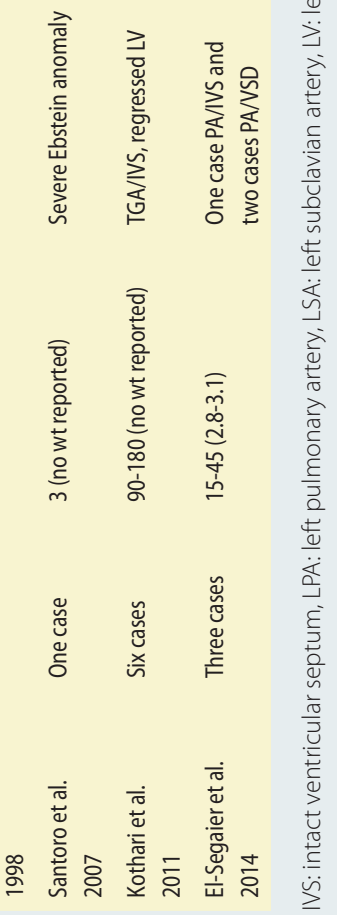


to balanced flow and development of both lung vasculatures ${ }^{13,14}$.

\section{Potential technical difficulties}

Crossing the $\mathrm{AD}$ with the PTCA wire can sometimes be difficult. Hypothetically, this is more likely if the $\mathrm{AD}$ origin from subclavian artery or the $\mathrm{AD}$ is curved. Despite that, and though in two of our cases the $\mathrm{AD}$ originated from the left subclavian artery and were curved, they could be easily crossed using choice PTCA wire. Additionally, withdrawal of the balloon catheter after deployment of the stent can be difficult (as in case 3). The challenge could be overcome by holding the tip of the long sheath against the stent while gently pulling back the deflated balloon. Deployment of an additional stent to cover the entire $\mathrm{AD}$ was not easy, as we feared that this manoeuvre might lead to forward migration of the implanted stent (case 2). This underlines the need for making more effort to estimate the length of the duct and needed stent.

\section{Potential risks and complications}

During crossing of the $\mathrm{AD}$, irritation to the ductal intima may result in sudden spasm and total occlusion of the duct ${ }^{3,6}$. Its occlusion can be life-threatening, as we experienced in the third case. Another potential complication is tearing or dissection of the ductal wall by the wire or catheter. Thrombus formation within the stent is another serious risk. It may happen immediately during the procedure (as in the second case) or later despite thrombosis prophylaxis with anti-platelet aggregation therapy. The recently occluded stent can be reopened by the use of a thrombolytic agent or by dilatation with a non-compliant balloon at higher pressure ${ }^{3}$. Furthermore, stent embolization and migration may occur during deployment ${ }^{3}$.

The growth and morphology of pulmonary artery branches may get distorted or even totally obliterated after ductal stenting ${ }^{14}$. Two of our cases (cases 2 and 3) had moderate stenosis of the left pulmonary artery from the start. With ductal stenting we could abolish the stenosis and save the vessels from total occlusion. Later, at the time of corrective surgery, these vessels could be reconstructed and dilated.

\section{Midterm thrombosis prophylactic therapy}

Different authors have suggested thrombosis prophylaxis after AD stenting by a combination of aspirin and clopidogrel, but the dose of clopidogrel is somewhat controversial. We used clopidogrel at $0.5 \mathrm{mg} / \mathrm{kg}$ per day ${ }^{9}$. A recent study challenged the need for such a "high" dose and suggested $0.2 \mathrm{mg} / \mathrm{kg}$ per day instead ${ }^{15}$. A multi-centre, double-blind, randomized study published in 2013 disputed even the need to add clopidogrel to the usual aspirin treatment ${ }^{16}$.

\section{Limitations of the study}

We are aware that this is a relatively new technique and the number of patients is still too small for drawing general conclusions. Therefore, larger patient series and long-term follow-up are warranted.

\section{CONCLUSIONS}

Arterial duct recanalization and stenting is feasible and effective in supplying an additional blood source to the pulmonary circulation. The procedure has some risks, but they can be minimized and treated successfully. Large patient series and long-term studies are required to evaluate the potential benefits of such intervention.

\section{ACKNOWLEDGEMENT}

We acknowledge Dr. Shehla Jadoon, assistant consultant, Department of Paediatric Cardiology, King Fahad Medical City, PSHC, Riyadh, and Ms. Vivienne Vella, head cath-lab technician, for their help in the data collection.

Additionally, we acknowledge Dr. Amin Bredan, VIB Inflammation Research Center and Ghent University, Department of Biomedical Molecular Biology, Ghent, Belgium for the editing of the article.

\section{REFERENCES}

1. Moulaert A, Senders R, Van Ertbruggen I, Huysmans $\mathrm{H}$, Harinck E. Effect of $\mathrm{E} 1$ type prostaglandin on hypoxemia in a cyanotic congenital cardiac malformation. Eur J Cardiol 1977; 5: 321-5.

2. McKenzie ED, Khan MS, Samayoa AX, Vener DS, Ishak YM, Santos AB, Heinle JS, Fraser $C D$. The Blalock-Taussig shunt revisited: a contemporary experience. J Am Coll Surg 2013; 216: 699-4.
3. Alwi M. Stenting the ductus arteriosus: Case selection, technique and possible complications. Ann Pediatr Cardiol 2008; 1: 38-45.

4. Santoro G, Palladino MT, Russo MG, Calabrò R. Neonatal patent ductus arteriosus recanalization and stenting in critical Ebstein's anomaly. Pediatr Cardiol 2008; 29: 176-9.
5. Kampmann C, Wippermann CF, Schmid FX. Transcatheter recanalisation and stenting of a closed ductus arteriosus in duct dependent lung perfusion. Heart 1998; 80: 206-7.

6. Kothari SS, Ramakrishnan S, Senguttuvan NB, Gupta SK, Bisoi AK. Ductal recanalization and stenting for late presenters with TGA intact ventricular septum. Ann Pediatr Cardiol 2011; 4: 135-8. 
7. Galal O, Kalloghlian A, Pittapilly BM, Dzimiri N. Phentolamine improves clinical outcome after balloon valvuloplasty in patients with critical pulmonary stenosis.

Cardiol Young 1999; 9: 127-8.

8. Galal MO, Alzahrani AM, Elhoury ME. Angiotensin converting enzyme inhibitor as an additive treatment after successful balloon dilation of a critical pulmonary valve stenosis.

J Saudi Heart Assoc 2012; 24: 47-50.

9. Martens L, Eyskens B, Boshoff D, Gewillig M Safety and efficacy of clopidogrel in children with heart disease.

J Pediatr 2008; 153: 61-4.

10. Gibbs JL, Rothman MT, Rees MR, Parsons JM, Blackburn ME, Ruiz CE. Stenting of the arterial duct: a new approach to palliation for pulmonary artery.

Br Heart J 1992; 67: 240-5.
11. Schneider M, Zartner P, Sidiropoulos A, Konertz W, Hausdorf G. Stent implantation of the arterial duct in newborns with duct-dependent circulation. Eur Heart J 1998; 19: 1401-9.

12. Gewillig M, Boshoff DE, Dens J, Mertens L, Benson LN. Stenting the neonatal arterial duct in duct-dependent pulmonary circulation: new techniques, better results. J Am Coll Cardiol 2004; 43: 107-12.

13. Santoro G, Capozzi G, Caianiello G, Palladino MT, Marrone C, Farina G, Russo MG, Calabrò R. Pulmonary artery growth after palliation of congenital heart disease with duct-dependent pulmonary circulation: arterial duct stenting versus surgical shunt. J Am Coll Cardiol 2009; 54: 2180-6.

14. McMullan DM, Permut LC, Jones TK, Johnston TA, Rubio AE. Modified
Blalock-Taussig shunt versus ductal stenting for palliation of cardiac lesions with inadequate pulmonary blood flow. J Thorac Cardiovasc Surg 2014; 147: 397-401.

15. Li JS, Yow E, Berezny KY, Bokesch PM, Takahashi M, Graham TP Jr, Sanders SP, Sidi $D$, Bonnet $D$, Ewert $P$, Jennings $L K$, Michelson AD; PICOLO Investigators. Dosing of clopidogrel for platelet inhibition in infants and young children: primary results of the Platelet Inhibition in Children On CLOpidogrel (PICOLO) trial. Circulation 2008; 117: 553-9.

16. Wessel DL, Berger F, Li JS, Dähnert I, Rakhit A, Fontecave S, Newburger JW CLARINET Investigators. Clopidogrel in infants with systemic-topulmonary-artery shunts. N Engl J Med 2013; 368: 2377-84. 